\title{
Publisher Correction: Germline de novo mutation clusters arise during oocyte aging in genomic regions with high double-strand-break incidence
}

Jakob M. Goldmann (D), Vladimir B. Seplyarskiy, Wendy S. W. Wong, Thierry Vilboux, Pieter B. Neerincx (D, Dale L. Bodian, Benjamin D. Solomon, Joris A. Veltman, John F. Deeken, Christian Gilissen (D) and John E. Niederhuber

Correction to: Nature Genetics https://doi.org/10.1038/s41588-018-0071-6, published online 5 March 2018.

In the HTML version of the article originally published, the figures for Supplementary Figures 1-15 were incorrect and did not match the correct figures in the PDF of Supplementary Text and Figures. The error has been corrected in the HTML version of the article.

Published online: 23 July 2021

https://doi.org/10.1038/s41588-021-00905-z

(๑) The Author(s), under exclusive licence to Springer Nature America, Inc. 2021 